Journal of Animal and Veterinary Advances 10 (2): 262-268, 2011

ISSN: $1680-5593$

(C) Medwell Journals, 2011

\title{
Sequence Characterization and Expression Pattern of the Capra hircus (Goat) RAB14, RB11b and SOD3 Genes
}

\author{
G.Y. Liu \\ Key Laboratory of Animal Nutrition and Feed of Yunnan Province, \\ Yunnan Agricultural University, Kunming 650201, China
}

\begin{abstract}
The complete CDS sequences of three goat genes-goat RAB14, RB11B and SOD3 were amplified using RT-PCR. Sequence analysis of these three genes revealed that the goat RAB14 gene encodes a protein of 215 amino acids and has high homology with the Ras-related protein Rab-14 ("RAB14) of seven species-rat and pig (100\%) human, mouse, chicken and orangutan (99\%), dictyostelium discoideum (71\%). The goat RB1B gene encodes a protein of 218 amino acids and has high homology with the Ras-related protein Rab-11B (RB11B) of five species-human, rat and bovine (99\%), mouse $(98 \%)$, electric ray $(97 \%)$. The goat SOD3 has high homology with the superoxide dismutase 3, extracellular (SOD3) of four species-rabbit (74\%), human $(74 \%)$, rat $(61 \%)$ and mouse $(60 \%)$. The phylogenetic tree analysis revealed that the goat RAB14 gene has a closer genetic relationship with the RAB14 gene of rat and pig and the goat RB1B gene has a closer genetic relationship with the $\mathrm{RB} 11 \mathrm{~B}$ of human, rat and bovine. The goat SOD3 gene has a closer genetic relationship with the SOD3 of rabbit. The gene expression profile analysis indicated that the goat RAB14, RB11B and SOD3 genes were differentially expressed in tissues including ovary, pituitary, muscle, kidney, heart, lung, liver and spleen. The experiment established the primary foundation for further research on these three goat genes.
\end{abstract}

Key words: Goat, RAB14, RB11B, SOD3, gene expression profile, phylogenetic tree, China

\section{INTRODUCTION}

RAB14 is an important GTPases which are localized to biosynthetic compartments, including the rough $\mathrm{ER}$, the Golgi complex and the trans-Golgi network and to endosomal compartments, including early endosomal vacuoles and associated vesicles.

RAB14 had been believed to function in both the biosynthetic and recycling pathways between the Golgi and endosomal compartments (Junutula et al., 2004; Proikas-Cezanne et al., 2006; Kyei et al., 2006). RB11B regulates the recycling pathways from endosomes to the plasma membrane and to the trans-Golgi network and is also thought to function in the histamine-induced fusion of tubulovesicles containing $\mathrm{H}+, \mathrm{K}+\mathrm{ATPase}$ with the plasma membrane in gastric parietal cells and in insulinstimulated insertion of GLUT4 in the plasma membrane of cardiomyocytes (Duman et al., 1999; Gromov et al., 1998; Bhartur et al., 2000; Palmieri et al., 2006).

SOD3 encodes a member of the Superoxide Dismutase (SOD) protein family. SODs are antioxidant enzymes that catalyze the dismutation of two superoxide radicals into hydrogen peroxide and oxygen. The product of this gene is thought to protect the brain, lungs and other tissues from oxidative stress. The protein is secreted into the extracellular space and forms a glycosylated homotetramer that is anchored to the Extracellular Matrix (ECM) and cell surfaces through an interaction with heparan sulfate proteoglycan and collagen (Cheng et al., 2006; Serra et al., 2003; Di Massimo et al., 2006).

Based on above described about these three genes, it is necessary to isolate these three genes from goat for they are associated with health, caveolar trafficking, neutrophil respiratory burst, fusion of tubulovesicles and other important functions. These functions are potentially related with the goat production. But until today the goat RAB14, RB11B and SOD3 genes have not been reported yet.

In present experiment, we will isolate the coding sequences of goat goat RAB14, RB11B and SOD3 genes, subsequently perform some necessary sequence analysis and finally conduct the tissue expression analysis for these three genes. These will establish the primary foundation of understanding these three goat genes.

\section{MATERIALS AND METHODS}

Samples collection, RNA extraction and first-strand cDNA synthesis: The tissue samples of ovary, pituitary, muscle, kidney, heart, lung, liver and spleen were derived 
from one mature Yunling goat (A Yunnan local black goat breed). Total RNA extraction and first-strand cDNA synthesis for these tissue samples were performed as the methods describe by Liu et al. (2004).

Isolation of coding sequences for the goat RAB14, RB11B and SOD3 genes: The RT-PCR was performed to isolate these three goat genes using the pooled cDNAs from different tissues above. The $25 \mu \mathrm{L}$ reaction system was: $2.0 \mu \mathrm{L}$ cDNA, $2.5 \mu \mathrm{L} 2 \mathrm{mM}$ mixed dNTPs, $2.5 \mu \mathrm{L}$ $10 \times$ Taq DNA polymerase buffer, $2.5 \mu \mathrm{L} 25 \mathrm{mMMgCl}_{2}$, $2.0 \mu \mathrm{L} 10 \mu \mathrm{M}$ forward primer, $2.0 \mu \mathrm{L} 10 \mu \mathrm{M}$ reverse primer, 2.0 units of Taq DNA polymerase $(1 \mathrm{U} / 1 \mu \mathrm{L})$ and $9.5 \mu \mathrm{L}$ sterile water. The primers for goat RAB14 gene isolation were designed based on the conserved CDS sequences information from rat and mouse RAB1 4 genes. Similarly, the primers for goat $\mathrm{RB} 11 \mathrm{~B}$ gene isolation were designed based on the conserved CDS sequences information from human, rat and mouse RB11B genes.

The primers for goat SOD3 gene isolation were designed based on the conserved CDS information from human and mouse SOD3 genes and the highly homologous goat EST sequences: EV444219, EV 437585 and EV443277. These primer sequences and their annealing temperature for RT-PCR reaction were shown in Table 1 .

Semi-quantitative RT-PCR: Semi-quantitative RT-PCR was performed as previously described elsewhere (Fehr et al., 2000; Daigo et al., 2006; Liu et al., 2005). About $25 \mu \mathrm{L}$ volumes consisting of the following reagents: 100 ng cDNA; $10 \times \mathrm{PCR}$ buffer (Sangon, Shanghai, China); $1.5 \mathrm{mM} \mathrm{MgCl}_{2} ; 25 \mu \mathrm{M}$ each of dATP, dCTP, dGTP and dTTP; $1.0 \mathrm{U}$ Taq polymerase (Sangon, Shanghai, China) and 10 pmol of each primer (Table 1). Amplification was done using a MJ Research PTC100 thermocycler (Watertown, MA, USA) under the following conditions: $4 \mathrm{~min}$ at $94^{\circ} \mathrm{C}$ followed by 25 cycles of $45 \mathrm{sec}$ at $94^{\circ} \mathrm{C}, 45 \mathrm{sec}$ at annealing temperature (Table 1), $1 \mathrm{~min}$ at $72^{\circ} \mathrm{C}$ and a final extension of $10 \mathrm{~min}$ at $72^{\circ} \mathrm{C}$. Amplification of $\beta$-actin (Accession no: OAU39357) was performed as a positive control. About $7 \mu \mathrm{L}$ PCR products were used to detect the expression pattern. Reaction products were electrophoresed through $1.5 \%$ agarose gels.

Sequence analysis: The cDNA sequence prediction was conducted using GenScan software (http://genes.mit.edu/ GENSCAN.html). The protein prediction and analysis were performed using the Conserved Domain Architecture Retrieval Tool of BLAST at the National Center for Biotechnology Information (NCBI) server (http://www. ncbi.nlm.nih.gov/BLAST) and the ClustalW software (http://www.ebi.ac.uk/ clustalw).
Table 1: Primers for goat RAB14, RB11B, SOD3 and $\beta$-actin genes and their annealing temperatures

\begin{tabular}{|c|c|c|}
\hline Gene & Primer sequence & $\mathrm{Tm} /{ }^{\circ} \mathrm{C}$ \\
\hline \multirow[t]{2}{*}{ RAB14 } & Forward: 5-ATGGCAACTACACCGTACAAC-3 & 58 \\
\hline & Reverse: 5-CTAGCAGCCACAGCC TTC-3 & \\
\hline \multirow[t]{2}{*}{ RB11B } & Forward: 5'-ATGGGCACCCGCGACGAC -3 & 54 \\
\hline & Reverse: 5'-TTAGATGTTCTG ACAGCACTG -3 & \\
\hline \multirow[t]{2}{*}{ SOD3 } & Forward: 5'-ATGCCGGCGCTGCTCTGT -3' & 54 \\
\hline & Reverse: 5'-TCAGACGTCCTTACACTC -3' & \\
\hline \multirow[t]{2}{*}{$\beta$-actin } & Forward: 5'-CTTGATGTCACGGACGATTT -3' & 56 \\
\hline & Reverse: 5'-CACGGCATTGTCACCAACT -3' & \\
\hline
\end{tabular}

\section{RESULTS AND DISCUSSION}

RT-PCR results for goat $\mathrm{RAB14}, \mathrm{RB11B}$ and SOD3 gene: Through RT-PCR with pooled tissue cDNAs from ovary, pituitary, muscle, kidney, heart, lung, liver and spleen, for goat RAB14, RB11B and SOD3 gene, the resulting PCR products were 648,657 and 735 bp (Fig. 1).

Sequence analysis: The cDNA nucleotide sequence analysis for these sequenced PCR products using the BLAST software at NCBI server (http://www.ncbi. nlm.nih.gov/BLAST) revealed that these genes were not homologous to any of the known goat genes and they were then deposited into the GenBank database (Accession number: EU244431, EU244432, EU559622). The sequence prediction was carried out using the GenScan software and results showed that these 648, 657 and 735 bp cDNA sequences represented three single genes which encoded 215,218 and 244 amino acids, respectively. The complete coding sequences of these genes and the encoded amino acids were shown in Fig. 2-4.

Further BLAST analysis of these proteins revealed that goat RAB14 has high homology with the Ras-related protein Rab-14 (RAB14) of seven species-rat and pig $(100 \%)$, human, mouse, chicken and orangutan $(99 \%)$, dictyostelium discoideum (71\%). The goat RB1B has high homology with the Ras-related protein Rab-11B (RB11B) of five species-human, rat and bovine (99\%), mouse $(98 \%)$, electric ray $(97 \%)$.

The goat SOD3 has high homology with the superoxide dismutase 3, extracellular (SOD3) of four species-rabbit (74\%), human (74\%), rat (61\%) and mouse $(60 \%)$ (Fig. 5-7). Based on the results of the alignment analyses of goat RAB14, RB11B and SOD3 genes, the phylogenetic trees were constructed using the ClustalW software (http:/www.ebi.ac.uk/clustalw), as shown in (Fig. 8).

The phylogenetic tree analysis revealed that the goat RAB1 4 has a closer genetic relationship with the RAB14 gene of rat and pig and the goat RB11B has closer genetic relationships with the $\mathrm{RB} 11 \mathrm{~B}$ of human, rat and bovine. The goat SOD3 has closer genetic relationships with the SOD 3 of rabbit. 

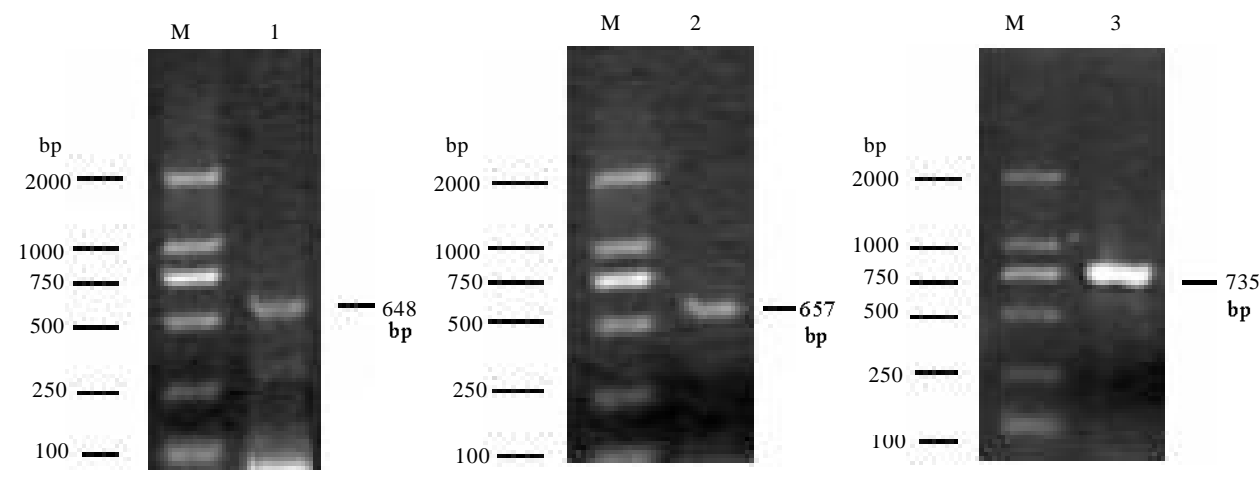

Fig. 1: RT-PCR results for goat RAB14, RB11B and SOD3 gene. M, DL2000 DNA markers; 1, PCR product for goat RAB1 4 gene ; 2, PCR product for goat RB11B gene; 3, PCR product for goat SOD3 gene

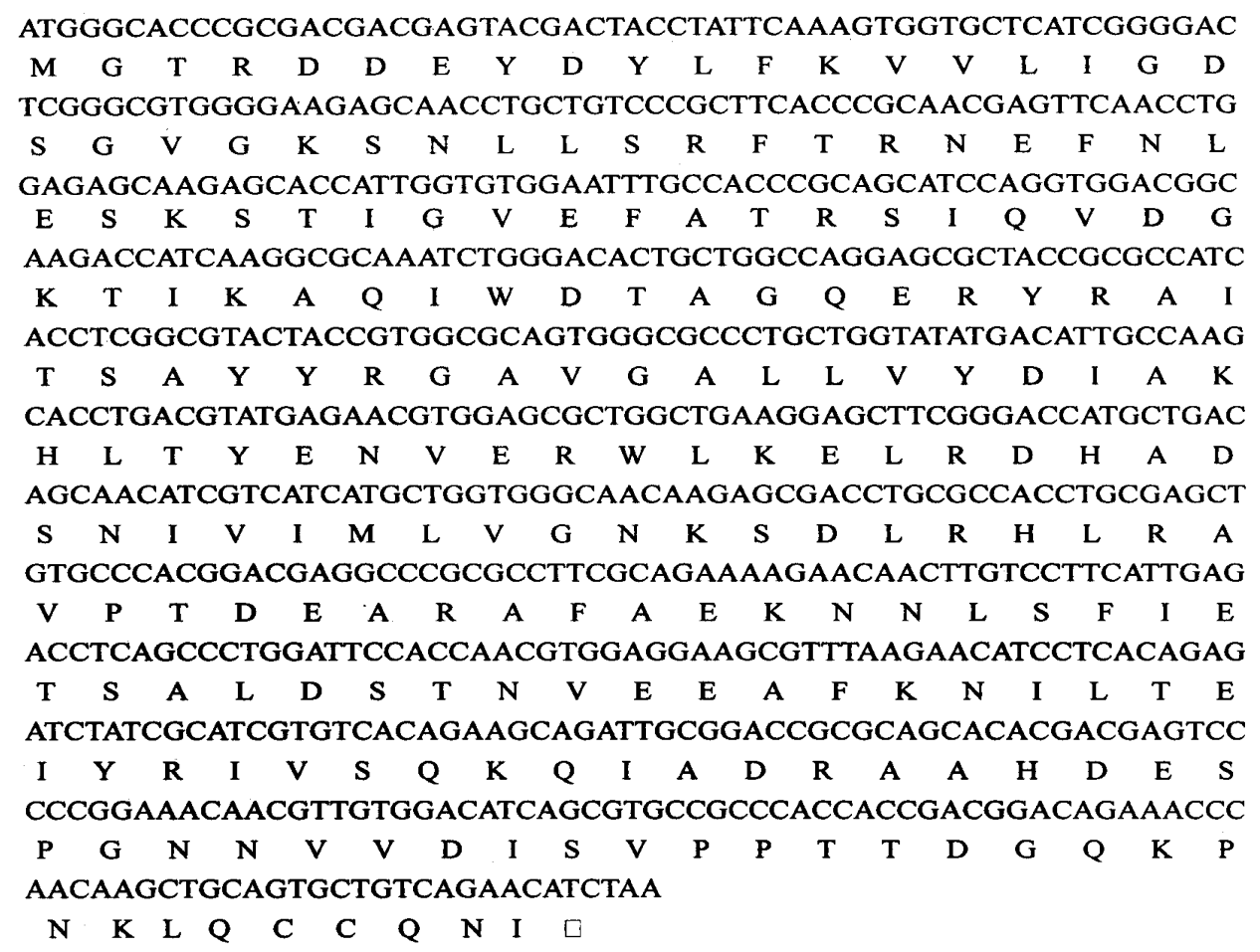

Fig. 2: The complete CDS of goat RAB1 4 gene and its encoding amino acids *indicates the stop codon

Tissue expression profile: Tissue expression profile analysis was carried out and results revealed that goat RAB14 gene was moderately expressed in ovary, muscle, heart, lung and liver, hardly expressed in pituitary, kidney and spleen.

The goat RB1B gene was highly expressed in kidney, heart, lung and hardly expressed in ovary, pituitary, muscle, liver, spleen. The goat SOD3 gene was highly expressed in ovary, pituitary, muscle and spleen, hardly expressed in kidney, heart, lung and liver
(Fig. 9). Comparative genomics is the analysis and comparison of genomes from different species. Researchers have learned a great deal about the function of human genes by examining their counterparts in simpler model organisms such as the mouse and some results has revealed that virtually all $(99 \%)$ of the protein-coding genes in humans align with homologs in mouse and over $80 \%$ are clear $1: 1$ orthologs (Hardison et al., 2003). This extensive conservation in protein-coding regions implied that this 
ATGGCAACTACACCGTACAACTACTCCTACATCTTTAAGTACATCATCATCGGGGAC

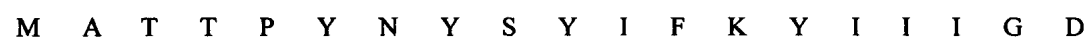
ATGGGAGTGGGGAAGTCCTGCCTGCTTCACCAGTTCACTGAGAAGAAGTTTATGGCT $\begin{array}{lllllllllllllllllll}M & G & \text { V } & \text { G } & \text { K } & \text { S } & \text { C } & \text { L } & \text { L } & \text { H } & \text { Q } & \text { F } & \text { T } & \text { E } & \text { K } & \text { K } & \text { F } & \text { M } & \text { A }\end{array}$ GACTGTCCTCACACAATTGGTGTTGAATTTGGTACAAGAATAATTGAAGTTAGTGGC $\begin{array}{lllllllllllllllllll}\text { D } & \text { C } & \text { P } & \text { H } & \text { T } & \text { I } & \text { G } & \text { V } & \text { E } & \text { F } & \text { G } & \text { T } & \text { R } & \text { I } & \text { I } & \text { E } & \text { V } & \text { S } & \text { G }\end{array}$ CAAAAAATCAAATTGCAGATCTGGGATACAGCAGGACAGGAGAGGTTCAGAGCTGTC $\begin{array}{lllllllllllllllllll}\text { Q } & \text { K } & \text { I } & \text { K } & \text { L } & \text { Q } & \text { I } & \text { W } & \text { D } & \text { T } & \text { A } & \text { G } & \text { Q } & \text { E } & \text { R } & \text { F } & \text { R } & \text { A } & \text { V }\end{array}$ ACACGAAGCTACTACAGAGGAGCCGCGGGAGCGCTGATGGTGTATGACATCACTAGG $\begin{array}{lllllllllllllllllll}\mathbf{T} & \mathbf{R} & \mathbf{S} & \mathbf{Y} & \mathbf{Y} & \mathbf{R} & \mathbf{G} & \mathbf{A} & \mathbf{A} & \mathbf{G} & \mathbf{A} & \mathrm{L} & \mathbf{M} & \mathbf{V} & \mathbf{Y} & \mathbf{D} & \mathbf{I} & \mathbf{T} & \mathbf{R}\end{array}$ AGAAGCACATATAATCACCTGAGCAGCTGGCTGACGGACGCCAGGAACCTCACCAAC $\begin{array}{lllllllllllllllllll}\mathbf{R} & \mathbf{S} & \mathbf{T} & \mathbf{Y} & \mathbf{N} & \mathbf{H} & \mathrm{L} & \mathbf{S} & \mathbf{S} & \mathbf{W} & \mathbf{L} & \mathrm{T} & \mathbf{D} & \mathbf{A} & \mathbf{R} & \mathbf{N} & \mathbf{L} & \mathbf{T} & \mathbf{N}\end{array}$ CCAAACACTGTGATAATCCTCATAGGGAATAAAGCAGATCTGGAGGCTCAGAGGGAT $\begin{array}{lllllllllllllllllll}\mathbf{P} & \mathbf{N} & \mathrm{T} & \mathbf{V} & \mathbf{I} & \mathbf{I} & \mathbf{L} & \mathbf{I} & \mathbf{G} & \mathbf{N} & \mathbf{K} & \mathbf{A} & \mathbf{D} & \mathbf{L} & \mathbf{E} & \mathbf{A} & \mathbf{Q} & \mathbf{R} & \mathrm{D}\end{array}$ GTGACGTATGAGGAAGCCAAACAGTTTGCTGAAGAAAATGGTTTATTGTTCCTTGAA $\begin{array}{llllllllllllllllllll}\text { V } & \text { T } & \text { Y } & \text { E } & \text { E } & \text { A } & \text { K } & \text { Q } & \text { F } & \text { A } & \text { E } & \text { E } & \text { N } & \text { G } & \text { L } & \text { L } & \text { F } & \text { L } & \text { E }\end{array}$ GCAAGTGCAAAAACGGGAGAGAACGTAGAAGATGCTTTCCTTGAGGCTGCCAAGAAG $\begin{array}{llllllllllllllllllll}A & S & A & K & T & G & E & N & V & E & D & A & F & \text { L } & \text { E } & \text { A } & \text { A } & \text { K } & \text { K }\end{array}$ ATCTATCAGAACATTCAGGATGGAAGCTTGGATCTGAACGCTGCCGAGTCTGGTGTA $\begin{array}{lllllllllllllllllll}\text { I } & \text { Y } & \text { Q } & \text { N } & \text { I } & \text { Q } & \text { D } & \text { G } & \text { S } & \text { L } & \text { D } & \text { L } & \text { N } & \text { A } & \text { A } & \text { E } & \text { S } & \text { G } & \text { V }\end{array}$ CAGCACAAACCTTCAGCCCCACAGGGGGGCCGGCTAACCAGCGAGCCCCAGCCCCAG $\begin{array}{lllllllllllllllllll}\mathrm{Q} & \mathrm{H} & \mathrm{K} & \mathrm{P} & \mathrm{S} & \mathrm{A} & \mathrm{P} & \mathrm{Q} & \mathrm{G} & \mathrm{G} & \mathrm{R} & \mathrm{L} & \mathrm{T} & \mathrm{S} & \mathrm{E} & \mathrm{P} & \mathrm{Q} & \mathrm{P} & \mathrm{Q}\end{array}$ AGGGAAGGCTGTGGCTGCTAG

$\begin{array}{llllllll}R & E & G & C & G & C & \square\end{array}$

Fig. 3: The complete CDS of goat RB11B gene and its encoding amino acids *indicates the stop codon

ATGCCGGCGCTGCTCTGTGCCTCTCTGCTCCTGGTGGCCTGTGCCTCGGCCGCCTCG $\begin{array}{lllllllllllllllllll}\text { M } & \text { P } & \text { A } & \text { L } & \text { L } & \text { C } & \text { A } & \text { S } & \text { L } & \text { L } & \text { L } & \text { V } & \text { A } & \text { C } & \text { A } & \text { S } & \text { A } & \text { A } & \text { S }\end{array}$ GCCGACCAGGTCCAGCAGCAGATGGGCTCCAACACGGAGGAGCAGATCCGCGACATG $\begin{array}{lllllllllllllllllllll}A & D & Q & V & Q & Q & Q & M & G & S & N & T & E & E & Q & I & R & D & M\end{array}$ CACGCCAAGGTGACGGAGATCTGGCAGGAGATGATGCAGCGGCAGGCGGCGGCCATC $\begin{array}{lllllllllllllllllll}\mathbf{H} & \mathbf{A} & \mathbf{K} & \mathbf{V} & \mathbf{T} & \mathbf{E} & \mathbf{I} & \mathbf{W} & \mathbf{Q} & \mathbf{E} & \mathbf{M} & \mathbf{M} & \mathbf{Q} & \mathbf{R} & \mathbf{Q} & \mathbf{A} & \mathbf{A} & \mathbf{A} & \mathbf{I}\end{array}$ GACCCGGACGCGGCGCTCCATGCGGTCTGCCGGGTGCTGCCGTCGGCCACGCTGGAG $\begin{array}{lllllllllllllllllll}\mathbf{D} & \mathbf{P} & \mathbf{D} & \mathbf{A} & \text { A } & \text { L } & \text { H } & \text { A } & \text { V } & \text { C } & \text { R } & \text { V } & \text { L } & \text { P } & \text { S } & \text { A } & \text { T } & \text { L } & \text { E }\end{array}$ GCGGAGCAGCCCCGGGTCAGCGGCCTCGTGCTCTTCCGGCAGCTCCGGCCTGGCGCC $\begin{array}{llllllllllllllllllll}A & \text { E } & \text { Q } & \text { P } & \text { R } & \text { V } & \text { S } & G & \text { L } & \text { V } & \text { L } & \text { F } & \text { R } & \text { Q } & \text { L } & \text { R } & \text { P } & \text { G } & \text { A }\end{array}$ CTGCTGGAGGCCTTCTTCCACCTTGAGGGCTTCCCGAACGAGCCCAACGGCACAAGC $\begin{array}{llllllllllllllllllll}\text { L } & \text { L } & \text { E } & \text { A } & \text { F } & \text { F } & \text { H } & \text { L } & \text { E } & \text { G } & \text { F } & \text { P } & \text { N } & \text { E } & \text { P } & \text { N } & \text { G } & \text { T } & \text { S }\end{array}$ CGCGCCATCCACGTGCACCAGTTTGGGGACCTGAGCCAGGGCTGCGACTCCACCGGG $\begin{array}{llllllllllllllllllll}\text { R } & \text { A } & \text { I } & \text { H } & \text { V } & \text { H } & \text { Q } & \text { F } & \text { G } & \text { D } & \text { L } & \text { S } & \text { Q } & \text { G } & \text { C } & \text { D } & \text { S } & \text { T } & \text { G }\end{array}$ CCGCACTACAACCCGATGTCCGTGCTGCACCCGCAGCACCCGGGCGACTTTGGCAAC $\begin{array}{llllllllllllllllllll}\mathbf{P} & \mathbf{H} & \mathbf{Y} & \mathbf{N} & \mathbf{P} & \mathbf{M} & \mathbf{S} & \mathrm{V} & \mathrm{L} & \mathbf{H} & \mathbf{P} & \mathbf{Q} & \mathbf{H} & \mathbf{P} & \mathbf{G} & \mathbf{D} & \mathbf{F} & \mathbf{G} & \mathrm{N}\end{array}$ TTCGCGGTGCGCGATGGCCAGGTCTGGAAGTACCGCTCCAACCTGGCTGCCTCGCTC $\begin{array}{llllllllllllllllllll} & \text { F } & \text { A } & \mathbf{V} & \mathbf{R} & \mathbf{D} & \mathbf{G} & \mathbf{Q} & \mathbf{V} & \mathbf{W} & \mathbf{K} & \mathbf{Y} & \mathbf{R} & \mathbf{S} & \mathbf{N} & \text { L } & \text { A } & \text { A } & \text { S } & \text { L }\end{array}$ ACCGGCCCGCACTCGATCGCGGGCCGTGCTGTGGTGGTCCACGCGGGCGAGGACGAC $\begin{array}{lllllllllllllllllllllllllll}T & G & \text { P } & \text { H } & \text { S } & \text { I } & \text { A } & G & R & A & V & V & V & H & A & G & \text { E } & \text { D } & \text { D }\end{array}$ CTGGGCCGCGGCGGCAATCAGGCCAGTCTGGAGAACGGTAACGCGGGACGCCGGCTT

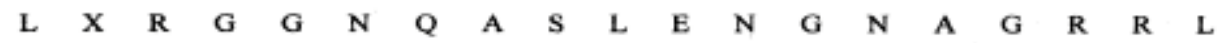
GCCTGCTGTGTGGTGGGTCTGTGCGGCCCCGGGCCCTGGGCGCACCAGGCGCAGGAG $\begin{array}{lllllllllllllllllll}A & C & C & V & V & G & \text { L } & \text { C } & \text { G } & \text { P } & \text { G } & \text { P } & \text { W } & \text { A } & \text { H } & \text { Q } & \text { A } & \text { Q } & \text { E }\end{array}$ AACGCGGAGCGCAAGAAGCGACGGCGCGAGAGCGAGTGTAAGGACGTCTGA

Fig. 4: The complete CDS of goat SOD3 gene and its encoding amino acids *indicates the stop codon

conservation of protein-coding sequences may be expected in different mammals such as including goat, dogs, cats, rabbits, monkeys and apes. This provides us a useful method to isolate the functional regions of 


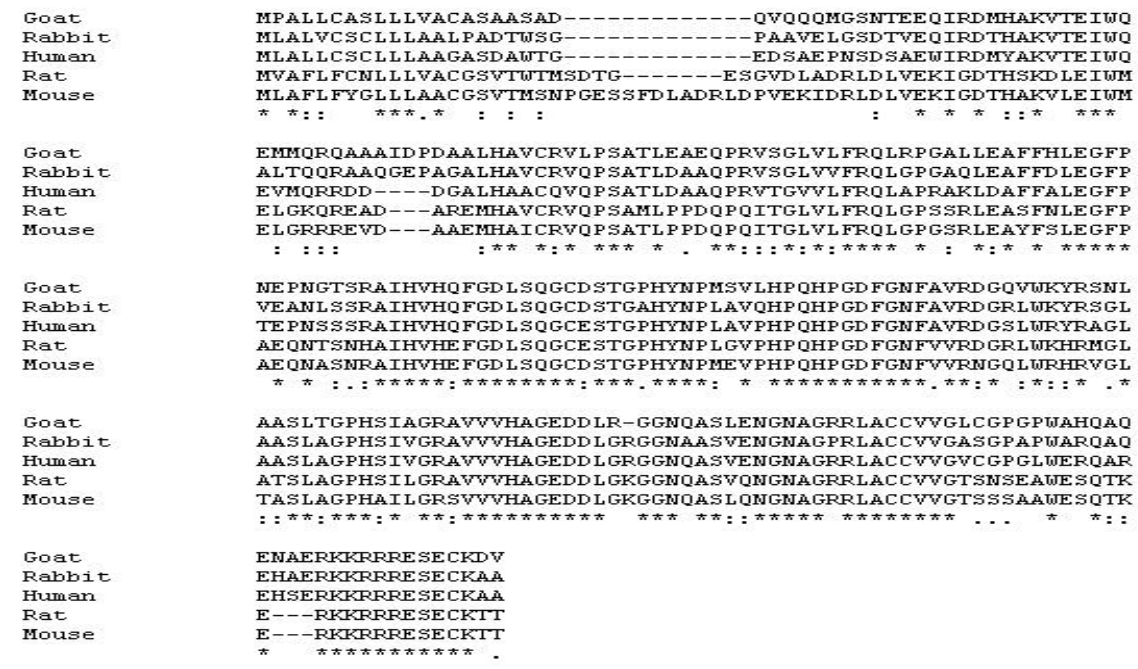

Fig. 7: The alignment of the protein encoded by goat SOD3 gene with the selected SOD3 proteins from other species
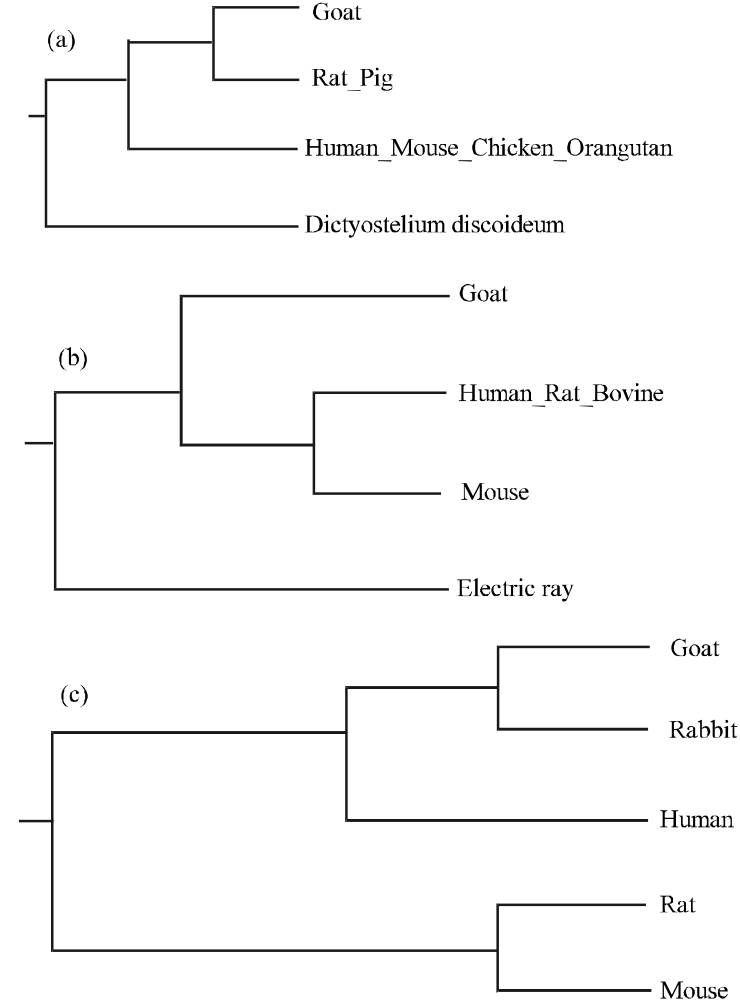

Fig. 8: The phylogenetic trees for selected goat RAB14, RB11B and SOD3 proteins. (a) phylogenetic tree analysis for selected RAB14 proteins; (b) phylogenetic tree analysis for selected RB11B proteins; (c) phylogenetic tree analysis for selected SOD3 proteins

that at the same time the biological activities of these three genes were presented diversely in different tissues.

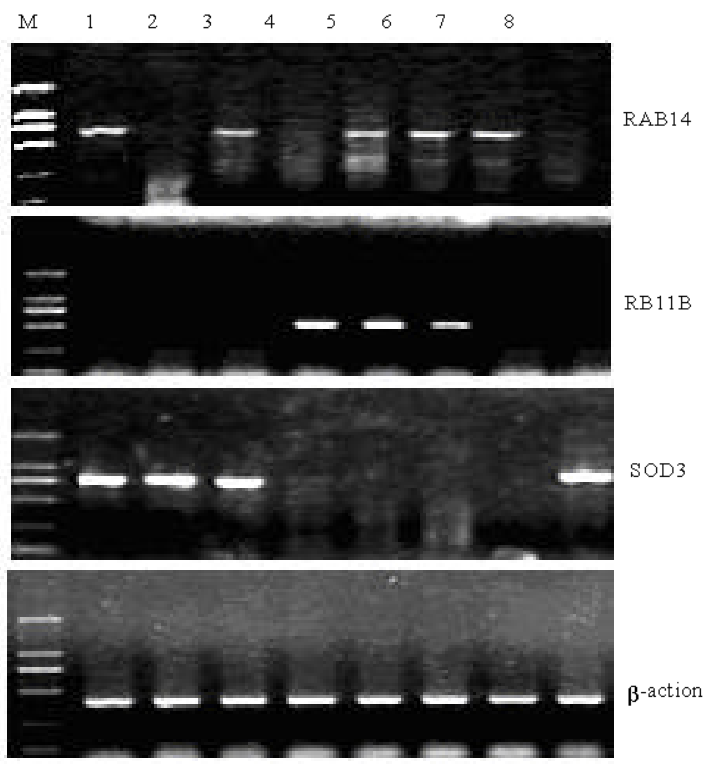

Fig. 9: Tissue expression distribution of the goat RAB14, RB11B and SOD3 gene. M, DL2000 markers; 1, ovary; 2 , pituitary; 3 , muscle; 4 , kidney; 5 , heart; 6 , lung; 7 , liver; 8 , spleen

\section{CONCLUSION}

In this study, we first isolated encoding regions of the goat RAB14, RB11B and SOD3 genes, performed necessary sequence analysis and tissue expression profile analysis for these three goat genes. This established theprimary foundation for further research on these goat genes. 


\section{REFERENCES}

Bhartur, S.G., B.C. Calhoun, J. Woodrum, J. Kurkjian, S. Iyer, F. Lai and J.R. Goldenring, 2000. Genomic structure of murine Rab11 family members. Biochem. Biophys. Res. Commun., 269: 611-617.

Cheng, Y.K., G.Y. Hwang, C.D. Lin, M.H. Tsai, S.W. Tsai and W.C. Chang, 2006. Altered expression profile of superoxide dismutase isoforms in nasal polyps from nonallergic patients. Laryngoscope, 116: 417-422.

Daigo, Y., I. Takayama, B.A. Ponder, C. Caldas, S.M. Ward, K.M. Sanders and M.A. Fujino, 2006. Differential gene expression in the murine gastric fundus lacking interstitial cells of Cajal. BMC Gastroenterol, 3: 14-14.

Di Massimo, C., R. lo Presti, C. Corbacelli, A. Pompei and P. Scarpelli et al., 2006. Impairment of plasma nitric oxide availability in senescent healthy individuals: Apparent involvement of extracellular superoxide dismutase activity. Clin. Hemorheol. Microcirc., 35: $231-237$.

Duman, J.G., K. Tyagarajan, M.S. Kolsi, H.P. Moore and J.G. Forte, 1999. Expression of rab1 1a N124I in gastric parietal cells inhibits stimulatory recruitment of the $\mathrm{H}^{+}-\mathrm{K}^{+}$-ATPase. Am. J. Physiol., 277: C361-C372.

Fehr, J.E., G.W. Trotter, J.T. Oxford and D.A. Hart, 2000. Comparison of Northern blot hybridization and a reverse transcriptase-polymerase chain reaction technique for measurement of mRNA expression of metalloproteinases and matrix components in articular cartilage and synovial membrane from horses with osteoarthritis. Am. J. Vet. Res., 61: 900-905.

Gromov, P.S., J.E. Celis, C. Hansen, N. Tommerup, I. Gromova and P. Madsen, 1998. Human rabl1a: Transcription, chromosome mapping and effect on the expression levels of host GTP-binding proteins. FEBS Lett., 429: 359-364.
Hardison, R.C., 2003. Comparative genomics. PLoS Biol., 1: e $58-\mathrm{e} 58$.

Junutula, J.R., A.M. de Maziere, A.A. Peden, K.E. Ervin and R.J. Advani et al., 2004. Rabl4 is involved in membrane trafficking between the Golgi complex and endosomes. Mol. Biol. Cell., 15: 2218-2229.

Kyei, G.B., I. Vergne, J. Chua, E. Roberts, J. Harris, J.R. Junutula and V. Deretic, 2006. Rabl 4 is critical for maintenance of Mycobacterium tuberculosis phagosome maturation arrest. EMBO J., 25: 5250-5259.

Liu, G.Y., Y.Z. Xiong, C.Y. Deng, B. Zuo and J.H. Zhang, 2004. Comparison of gene expression patterns in Longissimus dorsi of pigs between the high-parent heterosis cross combination Landrace $\times$ Large White and the mid-parent heterosis cross combination Large White $\times$ Meishan. Asian-Aust. J. Anim. Sci., 17: 1192-1196

Liu, Y.G., Y.Z. Xiong and C.Y. Deng, 2005. Isolation, sequence analysis and expression profile of a novel swine gene differentially expressed in the Longissimus dorsi muscle tissues from Landrace $\times$ Large White cross-combination. Acta Biochimica Biophys. Sinica, 37: 186-191.

Palmieri, D., A. Bouadis, R. Ronchetti, M.J. Merino and P.S. Steeg, 2006. Rab1la differentially modulates epidermal growth factor-induced proliferation and motility in immortal breast cells. Breast Cancer Res. Treat., 100: 127-137.

Proikas-Cezanne, T., A. Gaugel, T. Frickey and A. Nordheim, 2006. Rab14 is part of the early endosomal clathrin-coated TGN microdomain. FEBS Lett., 580: 5241-5246.

Serra, V., T. von Zglinicki, M. Lorenz and G. Saretzki, 2003. Extracellular superoxide dismutase is a major antioxidant in human fibroblasts and slows telomere shortening. J. Biol. Chem., 278: 6824-6830. 